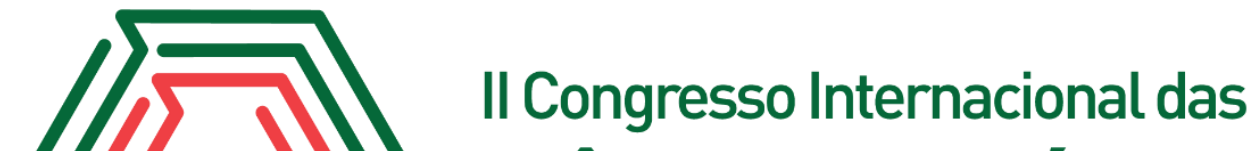 Ciências Agrárias COINTER - PDVAgro 2017
}

\section{DESEMPENHO DE CABRITOS LACTENTES EM DIFERENTES PERIODOS DE ACESSO AO CREEP FEEDING}

\author{
Apresentação: Pôster
}

\begin{abstract}
Denner Matos Roma ${ }^{1}$; Beatriz Almeida Teixeira ${ }^{2}$; Alisson Santos Vieira Lima ${ }^{3}$; Guilherme Rodrigues do Nascimento ${ }^{4}$; Aires Lima Rocha Neto ${ }^{5}$
\end{abstract}

\section{Introdução}

Sabe-se que a principal fase de desenvolvimento do animal é no período de amamentação. A exigência e o aporte nutricional que a matriz tem que dar para a cria é muito importante. Se uma matriz não estiver bem nutrida, o desenvolvimento do cabrito pode ser prejudicado.

Sendo assim, com o advento de técnicas de creep feeding (comedouro privativo), através de alimento concentrado, pode vir a ser uma solução altamente viável para corrigir a deficiência nutricional, e que as crias durante o período de amamentação possam apresentar um melhor desenvolvimento, crescimento e consequentemente, elevado peso a desmama.

O creep feeding pode ser iniciado nos primeiros dias de vida, contribuindo principalmente para a adaptação das crias ao consumo de alimentos sólidos e diminuir o estresse em decorrência da desmama.

Objetivou-se com este trabalho avaliar o efeito de diferentes períodos de acesso ao creep feeding, sobre consumo, ganho médio diário, peso a desmama e escore de condição corporal de cabritos da raça Anglo-Nubiana.

\section{Fundamentação Teórica}

O “creep feeding” é uma estratégia de alimentação exclusiva para animais durante a fase de cria, em cocho cercado, onde somente eles têm acesso ao alimento. A suplementação é feita através

\footnotetext{
${ }^{1}$ Estudante Bacharelado em Zootecnia, IF Baiano Campus Santa Inês, dennermatosroma@gmail.com

${ }^{2}$ Estudante Bacharelado em Zootecnia, IF Baiano Campus Santa Inês, bia.tecagropec@hotmail.com

${ }^{3}$ Estudante Bacharelado em Zootecnia, IF Baiano Campus Santa Inês, asvlima.al@gmail.com

${ }^{4}$ Docente Co-Orientador , IF Baiano Campus Santa Inês, guilherme.nascimento@ifbaiano.edu.br

${ }^{5}$ Docente Orientador, IF Baiano Campus Santa Inês, aires.rocha@si.ifbaiano.edu.br
} 
de concentrados e suplementos minerais e vitamínicos. A prática de suplementação melhora o desenvolvimento ponderal das crias durante a fase de amamentação (NERES et al., 2001).

Entretanto, segundo Borges et al., (2013) existem dúvidas sobre o tempo adequado de fornecimento dessa suplementação e a sua relação com as respostas dos cabritos especialmente na caprinocultura de corte.

Borges et al .,(2012) em trabalho que avaliou o desempenho ponderal de cabritos mestiços bôer em diferentes períodos de acesso ao creep feeding, 70 dias, 50 dias e 30 dias, respectivamente, ao analisar a variável ganho médio diário não foi notado diferença entre os tratamentos com período acesso ao creep feeding de 70 e 50 dias, 209 e 210 g, respectivamente, todavia apresentaram ganho médio diário superior e diferindo $(\mathrm{P}<0,05)$ do tratamento com período de acesso ao creep feeding de 30 dias que apresentou um ganho médio diário de 164 g. Portanto, é possível concluir neste trabalho que o retardo do fornecimento do alimento sólido influenciou na variável.

Além do mais, não se pode excluir a influência materna sobre o crescimento do cabrito, principalmente durante os dois primeiros meses de lactação. Portanto as características relacionadas ao crescimento são influenciadas por diversos fatores, dentre eles, o sexo, tipo de nascimento e idade da mãe ao parto, peso da mãe, ordem de parição (SANTANA et al., 1996).

Oliveira et al.,(2009) ao trabalharem com desempenho ponderal e características de crescimentos de cabritos da raça Anglo-Nubiana constataram que o tipo de nascimento exerceu influência sobre o peso ao nascer, bem como sobre o peso vivo até os 60 dias de idade, sendo que os animais provenientes de nascimento simples apresentaram peso vivo superior àqueles de nascimento duplo em 10,8\% e 18,2\%, aos 30 e 60 dias de idade.

\section{Metodologia}

O experimento foi conduzido nas instalações da (UEC) Unidade Educativa de Campo no Setor da Caprinocultura do Instituto Federal de Educação, Ciência e Tecnologia Baiano Campus Santa Inês, no município de Santa Inês-Ba. O período experimental foi desenvolvido entre os meses de abril a agosto de 2017.

A instalação do setor é composta de piso ripado elevado e com divisórias de madeira. Foram utilizados 40 cabritos da raça Anglo-Nubiana, distribuídos em quatro tratamentos, sendo o delineamento experimental inteiramente casualizado. No $1^{\circ}$ tratamento, totalizando 10 cabritos, 5 machos e 5 fêmeas que tiveram acesso somente ao aleitamento natural até o desmame. No $2^{\circ}$ tratamento, totalizando 10 cabritos, 6 machos e 4 fêmeas que tiveram acesso ao creep feeding por 
um período de 50 dias. No $3^{\circ}$ tratamento, totalizando 10 cabritos, 6 machos e 4 fêmeas tendo acesso ao creep feeding por um período de 70 dias. No $4^{\circ}$ tratamento, totalizando 10 cabritos, 5 machos e 5 fêmeas que tiveram acesso ao creep feeding do nascimento a desmama. O desaleitamento das crias ocorreu ao $90^{\circ}$ dia de vida, sendo o modelo de aleitamento natural contínuo.

Durante o período de trabalho os cabritos ficavam o tempo inteiro com as matrizes. O sistema de criação utilizado no setor foi o intensivo. As matrizes recebiam $600 \mathrm{~g}$ de ração concentrada comercial, fracionada duas vezes ao dia (às 09h00min e 17h00min horas) e feno de Tifton 85 (Cynodon spp.) ad libitum. Em cada baia dispunha de comedouro tipo PVC, bebedouro automático e saleiro do lado externo.

Após o nascimento, os cabritos receberam os cuidados pós-parto, sendo identificados com brinco na orelha direita, com o ano de nascimento e a respectiva ordem de nascimento. Além do acesso ao volumoso das matrizes em todos os tratamentos, as crias que tiveram acesso ao creep feeding, foi fornecido concentrado comercial peletizado (16\% PB) em quantidade gradativa ao peso do animal (equivalente $0,5 \%$ a $1,5 \%$ do peso vivo) e acesso dos mesmos se deu conforme a idade indicada em cada tratamento, sendo ofertadas duas vezes ao dia (às 08h00min e 16h00min horas).

Como forma de medir o consumo diário por tratamento, as sobras do concentrado foram devidamente retiradas e pesadas em uma balança com capacidade de $5 \mathrm{~kg}$ e precisão de $40 \mathrm{~g}$ no dia seguinte antes do fornecimento da dieta do respectivo dia.

As variáveis, peso vivo e escore de condição corporal, foram coletados ao nascimento e a cada 15 dias, até o $90^{\circ}$ dia de vida. Para a pesagem dos mesmos, utilizou-se de uma balança mecânica com capacidade máxima de $500 \mathrm{~kg}$ e precisão de 200 g. A determinação do escore da condição corporal foi através da apalpação da região lombar (apófises transversas e processos espinhosos), atribuindo nota de 1,00 a 5,00; sendo 1,00 para muito magro e 5,00 para muito gordo, com escala de 0,50, bem como descrito por (OSÓRIO et al., 1996).

Os dados foram submetidos a análises de variância e comparação entre médias realizada pelo teste de Tukey considerando o nível de probabilidade de erro 5\% utilizando o Sistema de Análises Estatísticas e Genéticas - SAEG (UFV, 2007).

\section{Resultados e Discussões}

Para a variável consumo de creep (g/dia), foram evidenciadas diferenças significativas $(\mathrm{P}<0,05)$ entre os tratamentos. O maior consumo foi observado no tratamento com período de acesso ao creep de 70 dias, demonstrando que o período de 20 dias de vida para início de 
fornecimento do creep é o mais recomendado para obterem-se os melhores índices de desempenho diário.

Houve diferença $(\mathrm{P}<0,05)$ entre os tratamentos, com relação ao ganho médio diário do nascimento a desmama. Os tratamentos com acesso ao creep feeding com um período de 50 e 70 dias e do nascimento a desmama, apresentaram valores de 119,89, 143,88 e 129,44, g/dia, respectivamente, conforme Tabela 1, e não diferindo estatisticamente entre si, além de apresentarem um GMD superior $(\mathrm{P}<0,05)$ ao tratamento sem acesso ao creep feeding. Corroborando assim, a importância da ingestão de alimento sólido, que influenciou significativamente no ganho médio diário. Sendo assim, para essa característica seria mais vantajoso o fornecimento de concentrado a partir dos 20 dias de idade.

A ingestão precoce de alimento sólido é de suma importância para iniciar o desenvolvimento dos pré-estômagos (rúmen, retículo, omaso), principalmente no desenvolvimento das papilas ruminais que está intimamente relacionada com a produção do ácido butírico, de modo a tornar o animal ruminante funcional de maneira precoce e que possa condicionar o mesmo à dieta com volumoso.

Para a característica peso a desmama, foram observadas diferenças significativas $(p<0,05)$ entre os tratamentos. O tratamento sem suplementação foi estatisticamente inferior aos tratamentos que tiveram acesso ao creep feeding, nos períodos de 70 e 90 dias de acesso ao creep Tabela 1, entretanto, não diferindo estatisticamente do tratamento com tempo de fornecimento do creep feeding no período de 50 dias devido ao baixo consumo de matéria seca e retardo no início do consumo de matéria seca.

Para a variável escore de condição corporal (ECC) na desmama os tratamentos sem acesso, 50 dias de creep e 90 dias de creep não apresentaram diferença entre si (p>0,05), Assim sendo, todos os tratamentos apresentaram escore de condição corporal ideal para essa fase de crescimento, conforme descrito por (BORGES et al .,2012), onde argumenta que o preconizado é um ECC acima de 2 nesta fase, possibilitando um bom desempenho produtivo aos animais em períodos posteriores.

Tabela 1. Valores médios de consumo (g/dia), ganho médio diário (GMD) do nascimento a desmama, peso inicial e a desmama (kg), escore de condição corporal (ECC), P-valor e coeficiente de variação de cabritos da raça Anglo-Nubiana desmamados aos noventa dias.

\begin{tabular}{|l|l|l|l|l|l|l|}
\hline \multicolumn{7}{|c|}{ Período } \\
\hline Acesso ao creep feeding & 0 dia & 50 dias & 70 dias & 90 dias & P-valor & CV $(\%)$ \\
\hline Consumo (g/dia) & - & $220.83^{\mathrm{B}}$ & $227.93^{\mathrm{A}}$ & $153.85^{\mathrm{C}}$ & 0,001 & 19,92 \\
\hline
\end{tabular}




\begin{tabular}{|l|l|l|l|l|l|l|}
\hline GMD do nascimento a desmama (g/dia) & $84,77^{\mathrm{B}}$ & $119,89^{\mathrm{A}}$ & $143,88^{\mathrm{A}}$ & $129,44^{\mathrm{A}}$ & 0,001 & 23,77 \\
\hline Peso inicial $(\mathrm{kg})$ & 3,10 & 2,81 & 3,00 & 3,53 & 0,198 & 21,12 \\
\hline Peso desmama $(\mathrm{kg})$ & $10,73^{\mathrm{B}}$ & $13,60^{\mathrm{AB}}$ & $15,95^{\mathrm{A}}$ & $15,18^{\mathrm{A}}$ & 0,002 & 21,73 \\
\hline ECC na desmama & $3,25^{\mathrm{B}}$ & $3,86^{\mathrm{AB}}$ & $4,33^{\mathrm{A}}$ & $4,00^{\mathrm{AB}}$ & 0,001 & 15,02 \\
\hline
\end{tabular}

Médias seguidas de letras distintas na mesma linha diferem estatisticamente entre si pelo teste de Tukey a $5 \%$ de probabilidade $(\mathrm{P}<0,05)$

\section{Conclusões}

Ressalta-se a importância do tempo de fornecimento do creep feeding por pelo menos 70 dias. De modo a aumentar o peso a desmama dos cabritos e melhorar o desempenho produtivo, entretanto há a necessidade de ser realizado um estudo da viabilidade econômica e da influência e interação do sexo, tipo de parto e ordem de parição no peso ao nascer, ganho médio diário e peso a desmama.

\section{Referências}

BORGES, G. D. S., et al. Desenvolvimento ponderal de cabritos lactentes com acesso ao creep feeding em diferentes idades. Synergismus scyentifica, UTFPR, 7(1) 2012.

BORGES, G. D. S, et al . Desenvolvimento ponderal e biométrico de cabritos lactentes com acesso ao creep feeding em diferentes idades. Revista Brasileira de Saúde e Produção Animal, 14(4), 745-754 2013.

NERES, M.A.; GARCIA, C.A.; MONTEIRO, A.L.G. et al. Níveis de feno de alfafa e forma física da ração no desempenho de cordeiros em creep feeding. Revista Brasileira de Zootecnia, v.30, n.3, p.941-947, 2001.

OLIVEIRA, D.F.;et al .Desenvolvimento ponderal e características de crescimento de caprinos da raça Anglonubiana criados em sistema semi-intensivo. Revista Brasileira de Saúde e Produção Animal., v.10, n.2, p.256-265, 2009.

OSÓRIO, J.C.S ; ALFRANCA, I.S.; SAÑUDO, C. et al. Efeito da procedência sobre o peso e conformação da carcaça em cordeiros. Revista Brasileira de Zootecnia. v.25, n.6, p.1187-1194. 1996.

SANTANA, A.F; MARTINS FILHO, R. Fatores que influenciam no desenvolvimento ponderal de ovinos jovens deslanados. Arquivos da Escola de Medicina Veterinária da UFBA, Salvador, v.18, n.1, p.41-60, 1995/1996.

UNIVERSIDADE FEDERAL DE VIÇOSA - UFV. Sistema para análise estatística e genéticaSAEG. Versão 9.1. Viçosa: Fundação Arthur Bernardes, 2007. 